BYRON RANGIWAI, ELIZABETH ALIIOAIGA, MOANA COOK, FIFITA LATU, \& MARYANNE TUKUTAU

\title{
The effects of the 2021 Delta lockdown in Aotearoa New Zealand: Some preliminary material to inform a future research question
}

\section{Introduction}

This paper is based on preliminary material gathered about the effects of the 2021 Delta lockdown in Aotearoa New Zealand. The preliminary material was gathered via a questionnaire and analysed using reflexive thematic analysis. This paper will offer some preliminary findings which are intended to inform a future research question. Appearing first in the Indian state of Maharashtra in December 2020 (Kupferschmidt \& Wadman, 2021), the Delta variant of COVID-19 was discovered to spread much more rapidly than the Alpha variant (Mahase, 2021; Summers et al., 2021). The Delta variant become predominant around the world (Campbell et al., 2021; Kang et al., 2021; Liu \& Rocklöv, 2021) but has since been replaced as the dominant variant (in the US and many other places

Byron Rangiwai is a Senior Lecturer in the School of Healthcare and Social Practice at Unitec Institute of Technology.

Elizabeth Aliioaiga, Moana Cook, Fifita Latu, and Maryanne Tukutau are postgraduate students in the School of Healthcare and Social Practice at Unitec Institute of Technology, and practitioners in their respective communities. 
at the time of writing this article) by Omicron (Thompson et al., 2022). Indeed, by March 2022, Omicron will infect a large percentage of the world's population (Murray, 2022).

Other countries have demonstrated that a rapid lockdown-regional or nationwide-is effective for coping with Delta outbreaks when combined with extensive public health measures such as physical separation, mass mask use, and vaccination (Summers et al., 2021). In 2021, a four-level alert system was in place in Aotearoa New Zealand. The use of lockdown to limit the spread of the virus was part of Level 4 of the alert system (Grout et al., 2021; Summers et al., 2021).

A community case of the Delta variant infection was discovered in Tāmaki Makaurau Auckland on August 17, 2021 (Grout et al., 2021). The number of reported cases quickly grew, and a series of superspreading events strained our contact tracing system, quarantine facilities, and health-care capacity (Grout et al., 2021). This outbreak necessitated a swift transition to a Level 4 lockdown for all of Aotearoa New Zealand to eliminate community transmission (Grout et al., 2021; Summers et al., 2021). Grout et al. (2021) argue that it was necessary for Aotearoa New Zealand to persist with "its intensive efforts to control the current outbreak" (para. 3). The lockdown was in place for several months for the entire country, while Tāmaki Makaurau Auckland remained in lockdown for nearly four months.

\section{Questionnaire}

To gather preliminary material about the impacts of the Delta lockdown in Aotearoa New Zealand, the authors devised a questionnaire composed in 
Google Forms. The questionnaire was entitled "Impacts of the Delta lockdown in Aotearoa New Zealand" and was shared via Facebook during the Delta lockdown. Responses were received from 119 individuals. The questions asked were:

- On a scale of $1-5$, how has the impact of the Delta lockdown affected you overall?

- What are some of the feelings you have experienced during Delta lockdown?

- How has your life been disrupted by Delta lockdown?

- How do you cope with Delta lockdown?

- Have you experienced any differences between the big lockdown in 2020 and the Delta lockdown in 2021? If so, what have you noticed?

\section{Reflexive thematic analysis}

While reflexive thematic analysis is normally used to analyse and interpret data from interviews, we decided to use it to reveal themes in the preliminary material. It is intended that the themes revealed in this paper could be used to inform future research. In reflexive thematic analysis "themes are conceptualized as meaning-based patterns, evident in explicit (semantic) or conceptual (latent) ways" (Braun et al., 2019, p. 848). As "the output of coding-themes result from considerable analytic work on the part of the researcher to explore and develop an understanding of patterned meaning" (Braun et al., p. 848).

Braun et al. outline six phases of reflexive thematic analysis, which have been used here to analyse the preliminary material: 
- Familiarisation

- Generating codes

- Constructing themes

- Revising themes

- Defining themes

- Producing the report

The familiarisation process is, as its name suggests, about becoming familiar with the dataset, or in this case the preliminary material gathered from the questionnaire: "The process involves becoming 'immersed' in the data and connecting with them in different ways" (Braun et al., 2019, p. 852). As this paper deals only with preliminary material gathered from the questionnaire, we familiarised ourselves with the information by reading, re-reading, brainstorming, and through discussion with each other. The process included "'noticing' interesting features" (p. 852) and making relaxed but "thoughtful and curious" (p. 852) notes about what we (re)read.

The process of generating codes from the preliminary material required that we "succinctly and systematically" (Braun et al., 2019, p. 853) discovered and identified meaning in the questionnaire responses. The process involved attaching concise and clear codes to bits of information so that they could be arranged around emerging patterns of meaning (Braun et al., 2019). The process for constructing themes involved grouping similar codes together as 'building blocks' with which to construct themes that draw upon patterns of meaning to "tell a coherent, insightful story" (Braun et al., 2019, p. 854) about what the preliminary material reveals. 
Revising and defining themes are two phases of the process that go together: "The revising and defining phases seek to ensure that themes, and theme names, clearly, comprehensively and concisely capture what is meaningful" (Braun et al., 2019, p. 857). Revising themes included reviewing coded material pertaining to a theme to ensure that the information related to the central concept of the inquiry and to the preliminary material. The Producing the report stage of the process is not merely the write-up but is also a means of testing the overall cohesion of the themes in relation to the material (Braun et al., 2019).

The remainder of this paper will be based on the questionnaire itself. The following sections will be headed by each questionnaire question, and the themes that emerged from the preliminary material will be described and linked to the literature-except for the first question, which provides only a graph reflecting the responses.

On a scale of 1-5, how has the impact of the Delta lockdown affected you overall?

Out of 119 respondents, 118 responded to this question. The following graph is a reflection of those responses.

60

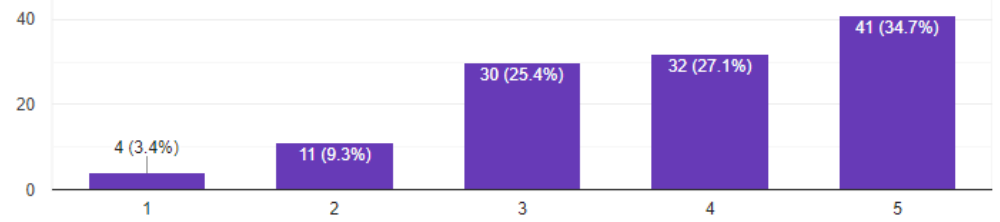

Figure 1: Google Forms graph showing responses. 
What are some of the feelings you have experienced during Delta lockdown?

Negative feelings

Common responses from the questionnaire showed that most of the participants experienced negative feelings during the Delta lockdown, including feelings of being sad, lonely, anxious, stressed, and angry. Kef (2021) argues that anxiety and negative emotions during the pandemic are a common occurrence. Many of the participants who experienced these negative emotions stated that their feelings of anxiety, loneliness, and stress came from the rise in "numbers of affected people", "not being able to be with friends and families", or "the spread of misinformation online".

Zhao and Zhou (2020) link the spread of misinformation online-especially on social mediawith experiences of negative emotions and the exacerbation of mental-health issues. Bogin and Varea (2020) opine that the fear and anxiety experienced during the pandemic can manifest as paranoia and stress.

The respondents indicated that they were affected, during the Delta lockdown, both mentally and physically, and suffered impacts on their overall sense of health and wellbeing. Concerning the impacts of the lockdown, some respondents reported that isolation from loved ones "affected me mentally", "added to my depression", or caused a lack of focus regarding work and/or study. ${ }^{1}$ Some respondents also described being "tired physically", suffering "fatigue", as well as "energy depletion".

1 See Rangiwai et al. (2020) for more about the impacts of COVID-19 on tertiary study. 
Positive feelings

A small number of respondents reported some positive feelings about the lockdown. Positive responses, while very few, included feelings of gratitude, peace, and relief. Underpinning these responses was an expression of a need for time to cater to and spend with family, and to enjoy homebased activities. Certainly, Lades et al. (2020) argue that the opportunity to spend time with family and engage in activities involving nature has stimulated positive feelings in some people despite the restrictions of lockdowns. Furthermore, Ammar et al. (2020) report that physical and social activities during lockdowns has been linked to an increase in positive emotions.

\section{Neutral feelings}

Some respondents reported neutral feelings toward the lockdown, expressing a need to "get on with it", "adapt to change", and "learn to live with the new normal". Indeed, research by Isaac et al. (2021) indicates that some people managed to adapt to the conditions generated by the pandemic.

How has your life been disrupted by Delta lockdown? Isolation

To deal with the effects of the pandemic, restrictions of movement and social distancing measures have been implemented worldwide (Moghadas et al., 2020). This pandemic has been described as the 'mother of all pandemics' (Matias et al., 2020) as the World Health Organization (WHO) and most governments recommended the entire human population stay home to reduce the spread of COVID-19 (Matias et al., 2020). Although social distancing and home isolation were essential to 
minimising the spread of the pandemic, concerns have been raised about the effects of prolonged isolation (Theodorou et al., 2021).

Most respondents described a deep sense of isolation connected to their inability to physically visit with family and friends due to the lockdown. Some of the responses included: "not being able to physically connect to whànau", "no physical contact with friends and family", "cut off from family", and "unable to see high-risk family members". The inability to be physically present to farewell deceased loved ones, celebrate the arrival of newborns, or to physically support elderly family members and friends, were also amongst the responses given. Certainly, the inability to attend tangihanga or other types of funeral rituals was a common sore point among respondents, despite the ability to attend proceedings online in some cases (Choi et al., 2021; Enari \& Rangiwai, 2021; Rangiwai \& Sciascia, 2021).

The experience of physical isolation was described by respondents as being overwhelmingly distressing. While respondents used technology to connect with others, in line with Choi et al.'s (2021) research, online interaction was considered insufficient. The ability to connect physically with family, friends, and others helps people to cope with stress, regulate emotions, and strengthen resilience (Matias et al., 2020). Isolation, on the other hand, may exacerbate anxiety and mental-health issues, and diminish immunity (Matias et al., 2020). Certainly, isolation and loneliness are associated with negative thoughts, anxiety, and depression (Hwang et al., 2020). 
Financial hardship

Lockdowns significantly affected rates of employment, which impacted on incomes (Fletcher et al., 2020). Many respondents indicated that their financial situation was impacted by the Delta lockdown, with answers such as "main income has been cut", "reduced pay", and "a drop in income". Other respondents reported that their household incomes were lessened when a spouse lost a job or when hours were reduced; the following three comments highlight this:

"My husband has stopped working which means he gets the wage subsidy which I am grateful for, but our income drops which meant we had to cut down on our shopping ..."

"My husband's job is not getting help from the government, so we are unsure he will have a job to go back to. Our savings are gone, the price of food has risen again ..."

"... husband lost his job, food at supermarkets have all gone up in price, so much ..."

Furthermore, financial stress and food insecurity were common concerns among low-income families, despite the provision of some government support during the lockdown (Choi et al., 2021).

Wellbeing

Studies have shown that isolation due to the pandemic may result in adverse psychological effects including post-traumatic stress symptoms, confusion, and anger, as well as an increase of depressive symptoms, stress, and sleep disruptions (Allé \& Berntsen, 2021). The inability to work during a lockdown, or losing a job, contributed to prolonged 
distress (Choi et al., 2021), while isolation generated significant mental distress, particularly for those with existing mental health concerns (Choi et al., 2021; Hwang et al., 2020).

Some respondents reported that they felt as though their mental and spiritual, as well as physical, health suffered during the lockdown. One respondent offered a particularly poignant response:

"I don't cope well if I'm not busy. I'm mild ADHD, and I can't focus on much as it is. So much time being overly self-reflective has not been healthy for me. I've lost my career and my income-again-as well. The pit I'm in is pretty deep."

While Choi et al.'s (2021) research shows that some people exercised and did more outdoor activities during a lockdown-beneficial to both mental and physical health (Hwang et al., 2021)-some respondents found this difficult. Some responses included:

"I have gained quite a bit of weight from comfort eating"

"exercising is harder because I lack motivation" "working online is stressful -I lost my drive to do well and ended up being teary and sad most of the time"

"I've turned to food and comfort eating to deal with my stress"

\section{Work-life balance (pros \& cons)}

One of the effects of COVID-19 is that working remotely has become essential in many organisations, with workers needing to rapidly adapt (Dockery \& Bawa, 2020). Working remotely has been shown to affect motivation, attitudes, and 
personal health and wellbeing (Spurk \& Straub, 2020). Comments from respondents aligned with the literature.

Most respondents found it challenging during the Delta lockdown to juggle work and home life, with many reporting a need to take care of, and assist with online learning for, children. Responses included:

"working from home is difficult because I can't
perform my normal duties"
"working from home has been harder as it's gone on"
"working from home is hard"
"working online is stressful"

Of those respondents who were able to work remotely, it was reported that they experienced difficulties regarding the blurring of work and home life, a point raised by Dockery and Bawa's (2020) research. In line with this, respondents struggled with and felt negative about working remotely, and one respondent commented: "working from home means getting mixed up between where and when work ends".

Further aligning with Dockery and Bawa's (2020) findings, respondents experienced conflict between work and family life, and found themselves exceeding their scheduled work hours. While setting boundaries between work and home life is beneficial (Dockery \& Bawab, 2020), most respondents seemed to struggle with this.

How do you cope with the Delta lockdown?

Coping mechanisms

The pandemic has significantly impacted on the way people live (Iddi et al., 2021). To deal with these 
changes, coping strategies are required (Iddi et al., 2021). Some coping strategies may include increasing spiritual activities, physical exercise, reading, healthy eating, and communicating more with friends and family (Iddi et al., 2021). Other coping strategies may include listening to music, engaging in hobbies, gardening, and completing household chores (Iddi et al., 2021).

Comments from respondents about how they coped with the Delta lockdown align with Iddi et al.'s (2021) research and include the following:

"I cope with health and wellness activities"

"I use walking, fitness, and eating healthy to cope"

"Spirituality, including karakia and meditation, is how I deal with it"

Furthermore, respondents also said that spending quality time with family, cleaning/decluttering homes, engaging in home projects, writing, reading, and focusing on work and study activities, were used as coping strategies during the Delta lockdown.

Respondents indicated that they engaged in activities that might best be described as forms of mindfulness, as a way of coping. Mindfulness is defined by Antonova et al. (2021) as "the awareness that arises when paying attention on purpose, in the present moment, and non-judgementally" (p. 3). Aspects of mindfulness include "observing and describing" (Antonova et al., 2020, p. 3). Observing is "noticing present moment experiences during daily activities such as walking or sensory stimuli such as smell or sights" (Antonova et al., 2021, p. 3). While describing refers to an individual's ability 
to express sensations, emotions, opinions, and beliefs (Antonova et al., 2021).

Mindfulness, Antonova et al. (2021) argue, can help to alleviate the effects of change, loss, and uncertainty. Aligned with Antonova et al.'s (2021) research, respondents reported using the following strategies:

"I breathe and take on one task at a time"

"I cry and I walk"

"I take time to notice the environment"

"I try to look for something new each day"

"I share emotions and feelings with family"

The respondents also indicated that expressing gratitude was an important coping strategy. Gratitude may be defined as an appreciation of the positive things in life (O'Leary \& Dockray, 2015). While mindfulness is a leading coping strategy, O'Leary and Dockray (2015) argue that expressing gratitude is also an effective approach to enhancing wellbeing during times of distress.

Respondents reported that it was important to express gratitude and acknowledge the positive factors present in their lives:

"focusing on the positives is important"

"I acknowledge other people are dealing with more severe problems"

"I'm thankful to the essential workers"

"I'm happy to still have a job"

\section{Virtual connection}

Due to the major and widespread disruption caused by the pandemic, there has been a significant shift from "physical and location-dependent interactions" 
to "virtual interactions" (Hacker et al., 2020, p. 563). This shift resulted in a surge in use of webconferencing systems such as Zoom and Microsoft Teams to enable remote working and learning (Hacker et al., 2020; Garbe et al., 2020). These technologies were also used for communication between families and friends in the form of "online socialising" and "online parties" (Hacker et al., 2020, p. 568).

In line with Hacker et al.'s (2020) findings, respondents reported that they took to "interacting with family and friends via technology" regularly, utilising online platforms such "Zoom, Face Time and Facebook messenger" to communicate. Respondents recounted using virtual forms of connection to engage in "family prayers", "family quiz nights", "online drinks with friends", "catchup with family members here and overseas", and to pursue other activities such as "online yoga". Certainly, Hacker et al. (2020) opine, virtual connections-such as those noted above-allowed people to remain connected and develop a "sense of togetherness" despite the physical distances caused by the pandemic (p. 568).

Regarding schooling, virtual connections enabled caregivers to "maintain routine for e-learning/homeschooling". This is despite issues balancing working from home with schooling at home, particularly with multiple children (Garbe et al., 2020; Serhan, 2020).

\section{Distress despite coping strategies}

Some respondents experienced feelings of "sadness, stress and panic" even while employing coping strategies such as exercising. One respondent stated: "despite exercising, eating healthy and 
talking to friends, I am not coping at all". Another respondent commented: "I seem ok on the surface, but tensions build and erupt, a lack of motivation sits on top of every meaningful pursuit, and it's difficult to get into a groove". Other respondents answered:

"I exercise when I am coping effectively and watching Netflix when I am not"

"Not coping well"

"Coping? No not at all"

\section{Escapism}

Fernandes et al. (2020) refers to escapism as a "form of avoidant coping aimed at dealing with stress by escaping unsatisfying life circumstances" (p. 60). Respondents indicated that they used online engagement-such as binge-watching content on Netflix and other streaming platforms, and online shopping - as a form of escapism. One participant said: "I use anime as a coping mechanism to escape into another world".

Social media platforms such as "Tik Tok, Instagram, and Facebook" were also used by participants as a way of escaping, with respondents reporting:

"I use dark memes and humour on social media to escape and pretend the pandemic isn't real"

"I use social media to escape from real life during lockdown"

Online gaming and other forms of gaming were also used by respondents as a way of escaping the realities of the Delta lockdown. Concerningly, Fernandes et al. (2020) assert that the pathological use of social media and gaming can exacerbate 
symptoms of depression, loneliness, and further escapism.

Respondents also indicated that "drugs and alcohol" were used more frequently during the Delta lockdown. Several respondents stated that although they used alcohol before the pandemic, they indicated that their rate of consumption significantly increased during the lockdown. Consistently, Rehm et al. (2020) state that financial hardship, social isolation, and uncertainties about the future following the pandemic have activated psychological distress, increasing the consumption of alcohol.

For some respondents, overeating was used as a coping mechanism. This point aligns with Modrzejewska et al.'s (2021) research, which argued that overeating was used by some people as a way of coping with pandemic restrictions. Overeating, Modrzejewska et al. (2021) argue, can provide a means of psychological escape and distraction from a stressful reality.

Have you experienced any differences between the big lockdown in 2020 and the Delta lockdown in 2021? If so, what have you noticed?

Emotions and concerns

Respondents stated that during the Delta lockdown they felt "scared" and "stressed", and levels of uncertainty were exacerbated by the frustration of "week-by-week extensions" enacted by the government. Stress is defined by Pfeifer et al. (2021) as "a state in which external demands exceed internal resources" thus inducing a "neuroendocrine stress response" (p. 581).

Interestingly, some respondents commented that they felt the lockdown of 2020 created a "sense of 
adventure", but they did not feel the same way in 2021, with several respondents commenting that they were "tired" and "fatigued".

The term 'fatigue' has been used by Michie et al. (2020) to describe what happens when people grow weary of pandemic restrictions. While Michie et al. (2020) found in their research that pandemic fatigue can cause people to adhere less to the lockdown rules, our respondents described feeling "less despairing and more resilient", with one respondent commenting that they felt "more hope overall".

One respondent remarked that people were "over social restrictions". Nitschke et al. (2021) argue that social connectedness during lockdown correlated with lower levels of stress. They found that during times of uncertainty, staying connected not only helped individuals deal with negative health and wellbeing issues, but improved resilience, something many of our respondents spoke positively about through the questionnaire.

\section{Preparedness and resilience}

While many respondents invoked adverse emotions, overall, the responses showed increased resilience and preparedness during the Delta lockdown. Moreover, some respondents felt that they knew what to expect so were ready: "I knew what it was all about this time, it wasn't like we were going into the unknown". Indeed, most respondents indicated that knowing what to expect helped them to cope with what was ahead: "I probably entered the 2021 lockdown knowing a bit more about how it would affect me and was better prepared". The responses align with Banerjee and Nair's (2020) work, which points out that stress is a natural response to a 
pandemic/disaster situation, but not being prepared can increase stress levels due to uncertainty.

According to Banerjee and Nair (2020), being prepared for any type of disaster will likely lessen its impact. Our respondents also reported that their employers seemed to be more prepared during the Delta lockdown than in previous lockdowns: "workwise it's a bit easier because we know what to do now". While others commented that they were better able to balance work and home commitments during the Delta lockdown due to being more prepared: "Last year I struggled to stay on top of kids' schoolwork along with my own studies, housework, and myself. This year I was somewhat better prepared".

Our respondents expressed a heightened sense of preparedness in 2021 , both mentally and with other commitments like work, with one respondent summing up: "I've been more prepared and accepting this time". Others commented that they have prepared their 'bubbles' and themselves this time around, highlighting the importance or preparedness: "being prepared is important and if you need help ask for it".

Social impact and the government response

As with any major catastrophic event, there is the potential for individuals to be adversely affected by the COVID-19 pandemic. One respondent recounted her experiences in 2020 and 2021:

"2020 lockdown I was being beaten up then living in my car/women's refuge barely eating and all of that. My ex-partner lost his shit. (I was on suicide watch in 2020 lockdown). This lockdown I'm in a safe and 
caring home. And I feel like I have less now than I ever did before and I feel like a shit human being because of it".

Banjaree et al. (2021) refer to the fact that a pandemic is not only a medical phenomenon, but that ongoing psycho-social effects have far-reaching implications for society. Mental-health issues, domestic violence, job losses and/or pay cuts resulting in decreased financial stability cause further strain on already over-stretched social services.

Respondents expressed concern for vulnerable communities and their ability to cope under even more pressure than before the pandemic began:

"I am more worried about our socially disadvantaged who are living below the poverty line or where being in lock-down in an unsafe environment is their reality".

Another respondent stated:

"I know that there is hardship, poverty and homelessness here in Aotearoa with plenty of people far worse impacted than I am. I worry more about social inequalities".

As for reactions to the government's response during the 2021 lockdown, comments suggested that the respondents perceived that the government was not supportive enough: "[there was] less help from the government for income supplements, other than that it's still as difficult as the first lockdown". Other comments comparing the 2020 lockdown to 2021 referred mostly to vaccinations, with respondents saying they felt "pressured by the 
government and society to get vaccinated", and that there seemed to be "more push for vaccinations by the government", or that the "focus on vaccinations had increased".

The government's vaccination programme rollout began in February 2021, with the intention of rolling out to the public from July 2021 with criticism being directed at the Ministry of Health for the slow pace of the campaign (Prickett et al., 2021). Vaccine hesitancy is a major issue in the slow uptake of COVID vaccinations and respondents commented on the "proliferation of conspiracy theories"2 and "misinformation". One respondent noticed "negativity since vaccines were introduced and people not taking this lockdown more seriously".

\section{Behaviour of others}

Our respondents commented often about the behaviour of others during the 2021 lockdown, indicating their dismay at those breaking the rules. Respondents described others as being, "complacent", "less phased" and used words like "rule breaking" and "disregard". One respondent reported hearing parties in their neighbourhood, while another commented that penalties were not harsh enough.

Kaim et al. (2021) found that the main incentive to staying home was to protect family and the health of the individual. For our respondents, the fear of catching COVID-19 contributed to increased compliance. However, Kaim et al.'s (2021) research shows that during successive lockdowns, compliance reduces. This is reflected in the

2 See Rangiwai (2021) for more on conspiracy theories and Māori during the pandemic. 
comments of our respondents, with one stating: "some people are more complacent because it's the second time around."

\section{Conclusion}

This paper is based on preliminary material gathered about the effects of the 2021 Delta lockdown in Aotearoa New Zealand. The intention of this paper is to present the preliminary material to inform the development of a future research question. This paper uses reflexive thematic analysis to discover themes and demonstrates that these themes are consistent with the extant literature. It is hoped that this paper will contribute, in some very small way, to the ongoing discourse concerning the impacts of COVID-19 in Aotearoa New Zealand. 


\section{References}

Allé, A. C. \& Berntsen, D. (2021). Self-isolation, psychotic symptoms and cognitive problems during the COVID-19 worldwide outbreak. Psychiatry Research, 302 (114015), 1-7. https://doi.org/10.1016/i.psychres.2021.11401 $\underline{5}$

Ammar, A., Brach, M., Trabelsi, K., Chtourou, H., Boukhris, O., Masmoudi, L., Bouaziz, B., Bentlage, E., How, D., Ahmed, M., Müller, P., Müller, N., Aloui, A., Hammouda, O., PaineirasDomingos, L. L., Braakman-Jansen, A., Wrede, C., Bastoni, S., Pernambuco, C. S., et al. (2020). Effects of COVID-19 Home Confinement on Eating Behaviour and Physical Activity: Results of the ECLB-COVID19 International Online Survey. Nutrients, 12(6), 1583. https://doi.org/10.3390/nu12061583

Antonova, E., Schlosser, K., Pandey, R., \& Kumari, V. (2021). Coping with COVID-19: Mindfulnessbased approaches for mitigating mental health crisis. Frontiers In psychiatry, 12, p.3. https://doi.org/10.3389/fpsyt.2021.563417

Banerjee, D., \& Nair, V. S. (2020). Handling the COVID-19 pandemic: Proposing a community based toolkit for psycho-social management and preparedness. Asian journal of psychiatry, 51(102152), 1-5. https://doi.org/10.1016/j.ajp.2020.102152

Bogin, B., \& Varea, C. (2020). COVID-19, crisis, and emotional stress: A biocultural perspective of their impact on growth and development for the next generation. American Journal of Human Biology,

$1-$

10. https://doi.org/10.1002/ajhb.23474 
Braun, V., Clarke, V., Hayfield, N. \& Terry, G. (2019). Thematic analysis. In P. Liamputtong (Ed.), Handbook of research methods in health social sciences (pp. 843-860). Springer Nature.

Campbell, F., Archer, B., Laurenson-Schafer, H., Jinnai, Y., Konings, F., Batra, N., Pavlin, B., Vandemaele, K., Van Kerkhove, M. D., Jombart, T., Morgan, O. \& de Waroux, O. L. P. (2021). Increased transmissibility and global spread of SARS-CoV-2 variants of concern as at June 2021. Eurosurveillance, $26(24)$. https://www.eurosurveillance.org/content/10.2 807/1560-7917.ES.2021.26.24.2100509

Choi, K., Giridharan, N., Cartmell, A., Lum, D., Signal, L., Puloka, V., Crossin, R., Gray, L., Davies, C., Baker, M. \& Kvalsvig, A. (2021). Life during lockdown: a qualitative study of lowincome New Zealanders'experience during the COVID-19 pandemic. The New Zealand Medical Journal, 134(1538), 52-67.

Dockery, M. \& Bawa, S. (2020). Working from Home in the COVID-19 lockdown. Bankwest Curtin Economics Centre Research Brief COVID-19. https://bcec.edu.au/assets/2020/05/BCECCOVID19-Brief-4_Working-from-home.pdf

Enari, D. \& Rangiwai, B. (2021). Digital innovation and funeral practice: Māori and Samoan perspectives during the COVID-19 pandemic. AlterNative, 17(2), 346-351. https://doi.org/10.1177/11771801211015568

Fernandes, B., Biswas, U. N., Mansukhani, R. T., Casarin, A. V., \& Essau, C. A. (2020). The impact of COVID-19 lockdown on internet use and escapism in adolescents. Revista de psicologia clínica con niños y adolescentes, 7(3), 60. 
https:/ / doi.org/10.21134/rpcna.2020.mon.205 6

Fletcher, M., Prickett, K. C. \& Chapple, S. (2020). Immediate employment and income impacts of Covid-19 in New Zealand: evidence from a survey conducted during the Alert level 4 lockdown. New Zealand

Economic Papers. https://doi.org/10.1080/00779954.2020.18705 $\underline{37}$

Garbe, A., Ogurlu, U., Logan, N., \& Cook, P. (2020). COVID-19 and remote learning: Experiences of parents with children during the pandemic. American Journal of Qualitative Research, 4(3), 51-61. https://doi.org/10.29333/ajqr/8471

Grout, L., Wilson, N., Summers, J., Kvalsvig, A., Baker, M. (2021, September 3). An upgrade Alert Level 2 is urgently needed to address the Delta variant threat. Public Health Expert. https://blogs.otago.ac.nz/pubhealthexpert/anupgraded-alert-level-2-is-urgently-needed-toaddress-the-delta-variant-threat/

Hacker, J., vom Brocke, J., Handali, J., Otto, M., \& Schneider, J. (2020). Virtually in this togetherhow web-conferencing systems enabled a new virtual togetherness during the COVID-19 crisis. European Journal of Information Systems, 29(5), 563-568. https://doi.org/10.1080/0960085X.2020.18146 $\underline{80}$

Hwang, T.J. , Rabheru, C.P. , Reichman, W. \& Ikeda, M. (2020). Loneliness and social isolation during the COVID-19 pandemic. International Psychogeriatrics. 32(10), 1217-1220. 
Iddi, S., Obiri-Yeboah, D., Aboh, I. K., Quansah, R., Owusu, S. A., Enyan, N. I. E., ... \& Armah, F. A. (2021). Coping strategies adapted by Ghanaians during the COVID-19 crisis and lockdown: A population-based study. Plos one, 16(6), e0253800.

https://doi.org/10.1371/journal.pone.0253800 Issac, V., Cheng, T., Townsin, L., Assareh, H., Li, A., \& McLachlan, C. S. (2021). Associations of the Initial COVID-19 Lockdown on Self-Reported Happiness and Worry about Developing Loneliness: A Cross-Sectional Analysis of Rural, Regional, and Urban Australian Communities. International Journal of Environmental Research and Public Health, 18. https://doi.org/10.3390/ijerph1818 9501

Kaim, A., Siman-Tov, M., Jaffe, E. \& Adini, B. (2021). Factors that enhance or impeded compliance of the public with governmental regulation of lockdown during COVID-19 in Israel. International Journal of Disaster Risk Reduction, 66(102596), 1-8. https://doi.org/ 10.1016/j.ijdrr.2021.102596

Kang, M., Xin, H., Yuan, J., Ali2, S. T., Liang, Z., Zhang, J.,Hu, T., Lau, E. H. Y., Zhang, Y., Zhang, M., Cowling, B. J., Li, Y., Wu, P. (2021). Transmission dynamics and epidemiological characteristics of Delta variant infections in China. $\quad B M J, \quad 1-26$. https://www.medrxiv.org/content/10.1101/202 $\underline{1.08 .12 .21261991 \mathrm{v} 1}$

Kef, K. (2021). COVID-19: The Level of Knowledge, Anxiety and Symptom Presentation. Psychology Research and Behavior Management, 14, 541548. https://www.dovepress.com/terms.php 
Kupferschmidt, K. \& Wadman, M. (2021). Delta variant triggers new phase in the pandemic. Science, 372(6549), 1375-1376. https://www.science.org/doi/abs/10.1126/scie nce.372.6549.1375

Lades, L. K., Laffan, K., Daly, M., \& Delaney, L. (2020). Daily emotional well-being during the COVID-19 pandemic. British Journal of Health Psychology, 25, 902-911. https://doi.org/10.1111/bjhp. 12450

Liu, Y. \& Rocklöv, J. (2021). The reproductive number of the Delta variant of SARS-CoV-2 is far higher compared to the ancestral SARS-CoV-2 virus. Journal of Travel Medicine, 1-3. https://doi.org/10.1093/jtm/taab124

Mahase, E. (2021). Delta variant: What is happening with transmission, hospital admissions, and restrictions? $B M J$, $1-2$. https://doi.org/10.1136/bmj.n1513

Matias, T., Dominski, F. H., Marks, D. F. (2020). Human needs in COVID-19 isolation. Journal of Health Psychology 25(7), 871-882.

Michie, S., West, R., \& Harvey, N. (2020). The concept of "fatigue" in tackling covid19. $B M J, 371$, $1-2$. https://doi.org/10.1136/bmj.m4171

Modrzejewska, A., Czepczor-Bernat, K., Modrzejewska, J., \& Matusik, P. (2021). Eating Motives and Other Factors Predicting Emotional Overeating during COVID-19 in a Sample of Polish Adults. Nutrients, 13(5), 1658. https://doi.org/10.3390/nu13051658

Moghadas, S.M. , Fitzpatrick, M.C. , Sa, P. , Pandey, A. , Shoukat, A., Burton, H. S. \& Galvani, P. (2020). The implications of silent transmission for the control of Covid-19 outbreaks. Proceedings of 
the National Academy of Sciences of the United States of America. 117(30), 17513-17515. https://www.pnas.org/content/pnas/117/30/1 7513.full.pdf

Murray, C. J. L. (2022). COVID-19 will continue but the end of the pandemic is near. The Lancet, 399(10323), 417-419.

https://doi.org/10.1016/S01406736(22)00100-3

Nitschke, J. P., Forbes, P. A., Ali, N., Cutler, J., Apps, M. A., Lockwood, P. L., \& Lamm, C. (2021). Resilience during uncertainty? Greater social connectedness during COVID-19 lockdown is associated with reduced distress and fatigue. British Journal of Health Psychology, 26(2), 553-569.

O'Leary, K., \& Dockray, S. (2015). The effects of two novel gratitude and mindfulness interventions on well-being. The Journal of Alternative and Complementary Medicine, 21(4), Pg, 1. https://doi.org/10.1089/acm.2014.0119

Pfeifer, L. S., Heyers, K., Ocklenburg, S., \& Wolf, O. T. (2021). Stress Research during the COVID-19 Pandemic and beyond. Neuroscience \& Biobehavioral Reviews, 131, 581-596. https://doi.org/10.1016/j.neubiorev.2021.09.0 45

Prickett, K. C., Habibi, H. \& Carr, P. A. (2021). COVID-10 vaccine hesitancy and acceptance in a cohort of diverse New Zealanders. Lancet, 10.1016/j.lanwpc.2021.100241.

Rangiwai, B. (2021). "Wake up, Sheeple!": Conspiracy theories and Māori during the COVID-19 pandemic. MAI Journal, 10(1), 46-49. 
https://doi.org/10.20507/MAIJournal.2021.10. 1.6

Rangiwai, B. \& Sciascia, A. (2021). The impacts of COVID-19 on tangihanga. Journal of Global Indigeneity, 5(1), 1-14. https://www.journalofglobalindigeneity.com/art icle/19435-the-impacts-of-covid-19-ontangihanga

Rangiwai, B., Simati-Kumar, B. \& Mataroa, R. (2020). The impacts of COVID-19 on the 2020 cohort of the Master of Applied Indigenous Knowledge programme at Te Wānanga o Aotearoa in Māngere. Te Kaharoa: The eJournal on Indigenous Pacific Issues, 13(1), 1-21. https://www.tekaharoa.com/index.php/tekahar oa/article/view/301

Rehm, J., Kilian, C., Ferreira-Borges, C., Jernigan, D., Monteiro, M., Parry, C. D., ... \& Manthey, J. (2020). Alcohol use in times of the COVID 19: Implications for monitoring and policy. Drug and Alcohol Review, 39(4), 301-304. https://doi.org/10.1111/dar.13074

Serhan, D. (2020). Transitioning from face-to-face to remote learning: Students' attitudes and perceptions of using Zoom during COVID-19 pandemic. International Journal of Technology in Education and Science, 4(4), 339.

Spurk, D. \& Straub, C. (2020). Flexible employment relationships and careers in times of the COVID19 pandemic. Journal of Vocational Behavior, 119. https://doi.org/10.1016/j.jvb.2020.103435

Summers, J., Wilson, N., Grout, L., Kvalsvig, A. \& Baker, M. (2021, August 31). Lessons from jurisdictions that are battling their own Delta variant outbreaks. Public Health Expert. https://blogs.otago.ac.nz/pubhealthexpert/less 
ons-from-jurisdictions-that-are-battling-theirown-delta-variant-outbreaks /

Theodorou, A. , Panno, A., Carrus, G. , Cabone, G. A. , Massullo, C. \& Imperatori, C. (2021). Stay home, stay safe, stay green: The role of gardening activities on mental health during the Covid-19 home confinement. Urban Forestry \& Urban Greening. 6(127091), 1-6. https://doi.org/10.1016/j.ufug.2021.127091

Thompson, M. G., Natarajan, K., Irving, S. A., Rowley, E. A., Griggs, E. P., Gaglani, M., Klein, N. P., Grannis, S. J., DeSilva, M. B., Stenehjem, E., Reese, S. E., Dickerson, M., Naleway, A. L., Han, J., Konatham, D., McEvoy, C., Rao, S., Dixon, B. E., Dascomb, K., Lewis, N. et al. (2022). Effectiveness of a third dose of mRNA vaccines against COVID-19-associated emergency department and urgent care encounters and hospitalizations among adults during periods of Delta and Omicron variant predominance VISION Network, 10 States, August 2021January 2022. MMWR, 71, early release, 1-8. https://stacks.cdc.gov/view/cdc/113718

Zhao, N., \& Zhou, G. (2020). Social Media Use and Mental Health during the COVID-19 Pandemic: Moderator Role of Disaster Stressor and Mediator Role of Negative Affect. Applied Psychology: Health and Well-Being, 12(4), 10191038. https://doi.org/10.1111/aphw.12226 